\title{
Correlation between Blood Pressure and Obesity Parameter against Cystatin- $C$ and Adiponectin Levels in Serum of Obese Adolescent
}

\author{
Ridwan $^{1,2}$, Ami Febriza ${ }^{2,3}$, Elmiana Bongga Linggi ${ }^{4}$, Rosdiana Natzir ${ }^{5}$, Nurpudji Astusti Taslim ${ }^{6}$ \\ ${ }^{1}$ Mappa Oudang Nursing Academy, Makassar, Indonesia \\ ${ }^{2}$ Postgraduate Doctoral Candidate of Medicine Science, Faculty of Medicine, Universitas Hasanuddin, Makassar, Indonesia \\ ${ }^{3}$ Department of Physiology, Faculty of Medicine, Universitas Muhammadiyah Makassar, Makassar, Indonesia \\ ${ }^{4}$ Nursing Science Study Program, Stella Maris School of Health Sciences of Higher Education, Makassar, Indonesia \\ ${ }^{5}$ Department of Biochemistry, Faculty of Medicine, Universitas Hasanuddin, Makassar, Indonesia \\ ${ }^{6}$ Department of Clinical Nutrition Science, Faculty of Medicine, Universitas Hasanuddin, Makassar, Indonesia
}

Background: Obesity contributes to the increased risk of chronic kidney and systemic inflammation. This condition can occur in obese adolescents. Most researches of cystatin- $\mathrm{C}$ (cys- $\mathrm{C}$ ) and adiponectin have been carried out in adult and children subjects. The purpose of this research is to determine differences in serum cys- $\mathrm{C}$ and adiponectin levels between obese and normoweight adolescents and their correlation with blood pressure and obesity parameters.

Materials and Methods: Twenty-eight obese adolescents and 22 normoweight adolescents aged 15-18 years old participated in this research. After the measurement of blood pressure and obesity parameters, we examined serum cys-C levels as a biomarker for decreased early stage renal function and adiponectin, an antiinflammatory adipokine. Estimated glomerular filtration rate (eGFR) based on serum cys-C is calculated using the eGFR-Chronic Kidney Disease Epidemiology Collaboration (eGFR-CKD EPI cys-C equation formula).

Results: Cys-C levels in obese adolescents were higher than normoweight adolescents. In contrast, serum adiponectin levels in obese adolescents were lower than for normoweight adolescents. Interestingly, eGFR based on serum cys-C showed no difference, although eGFR in obese adolescents was lower than normoweight adolescent. Serum cys-C was positively correlated with systolic blood pressure (SBP), diastolic blood pressure (DBP), body mass index (BMI) and waist circumference (WC). Serum adiponectin was negatively correlated with SBP, DBP, BMI and WC. SBP is a predictor factor for the increase in serum cys- $\mathrm{C}$ and $\mathrm{BMI}$ is a predictor factor in the decrease in serum adiponectin levels.

Conclusion: There is a decline in early stage kidney function and inflammation in obese adolescents as evidenced by increased serum cyst-C levels and decreased serum adiponectin levels. These two biomarkers correlate with blood pressure, $\mathrm{BMI}$ and WC and play a role in the pathomechanism of early stage impairment of kidney function and inflammation in obese adolescents.

Keywords: adiponectin, body mass index, cystatin- $C$, early stage renal diseases, inflammation, systolic blood pressure 


\section{Introduction}

In recent years, obesity has become a worrying epidemic health problem for adolescents. ${ }^{1}$ The prevalence of adolescents with overweight has increased worldwide, leading to a global health crisis not only in high-income countries, but also in low and middle income countries. ${ }^{2}$

Obesity contributes to the increased risk of several diseases including diabetes, hypertension, cardiovascular disease, metabolic syndrome ${ }^{3,4}$, dyslipidemia, oxidative stress and is a significant risk factor for kidney disorder ${ }^{3}$. Besides haemodynamic and inflammatory factors, metabolic effects are also associated with kidney disorders in obesity. ${ }^{4}$ All pathological processes in obesity-induced kidney disease contribute to albuminuria and progressive decline in kidney function which ultimately leads to glomerulosclerosis and kidney fibrosis. ${ }^{5}$ This is what underlies changes in kidney microcirculation, namely the occurrence of high glomerular flow and hyperfiltration. This change occurs in the early stages of obesity. ${ }^{6}$

In obese patients also experience a chronic systemic inflammatory process. $^{7}$ This is characterized by a disturbance in the expression of cytokines, chemokines, and complement proteins. Activation of non-specific immune system components can be considered as a factor that allows the development of obesity and inflammation. These mediators provide important systemic effects that can lead to insulin resistance, metabolic disorders and cardiovascular disease in obese patients. ${ }^{8}$

Like adults, obesity in adolescents can cause diabetes mellitus, hyperlipidemia, cardiovascular disease and renal disease. ${ }^{9}$ Various markers are used to find out the pathological processes in obesity including cystatin-C (cys-C) as biomarkers of early stage renal diseases (ESRD) $)^{10}$, and adiponectin as anti-inflammatory marker ${ }^{11}$. Cys-C is a low molecular weight protein $(13 \mathrm{kD})$ which is an endogenous proteininase inhibitor produced by all nucleating cells in the human body at a fairly constant level. Cys-C is filtered freely by the glomerulus and almost completely reabsorbed in the proximal tubule. ${ }^{12} \mathrm{Cys}-\mathrm{C}$ is not affected by age, sex, muscle mass, ethnic and inflammatory conditions. ${ }^{13}$ Cys-C is more appropriate for the determination of renal damage with a decrease in GFR than creatinine clearance. ${ }^{4}$ The National Kidney Foundation proposes to use cys- $\mathrm{C}$ to measure glomerular filtration rate (GFR) in a variety of clinical conditions in the youth population. ${ }^{14} \mathrm{Cys}-\mathrm{C}$ is increased in obesity and is associated with GFR. ${ }^{15}$
Adiponectin is the same as gelatin-binding protein of $28 \mathrm{kD}$ secreted by adipocytes. ${ }^{16}$ Adiponectin mainly modulates glucose and catabolism regulation of fatty acids $^{17}$, decreases endogenous cytokine production, inhibits endothelial cell proliferation, decreases angiogenesis, increases endothelial vasodilation, increases hepatic insulin action, increases oxidation in muscles and act as antiinflammatory ${ }^{18}$.

Previous studies reported that adiponectin serum was related to blood pressure and obesity parameters. Serum adiponectin levels were found to be lower in obese prepubertal groups ${ }^{19}$ and negative correlation with insulin resistance ${ }^{20}$. Low adiponectin levels have also been associated with metabolic syndrome and type 2 diabetes ${ }^{17,18}$ and tend to aggravate the inflammatory process in obese people ${ }^{8}$.

Most researches of cys-C and adiponectin have been carried out in adult and children subjects. The purpose of this research is to determine the differences in serum cys-C and adiponectin levels between obese and normoweight adolescents and their correlation with blood pressure and obesity parameters, including body mass index (BMI) and waist circumference (WC).

\section{Materials and methods}

\section{Subjects}

This study was a cross sectional study of Chinese ethnic adolescents in one of the high schools in Makassar, where the majority of students were classified as obese and overweight. A total of 50 adolescent boys and girls aged 15-18 years old participated in this research consisting of 28 obese adolescents and 22 normoweight adolescent. The criteria for the subjects in this research were not taking corticosteroid drugs; peroxisome proliferator-activated receptor (PPAR)- $\gamma$ agonist group; and thiazolidinedione (TDZ), not consuming fish oil regularly, not active smokers and do not suffer from goitre.

The research was carried out after obtaining recommendations for ethical approval from The Committee on Ethics of Medical Research, Faculty of Medicine, Hasanuddin University on March 16, 2013 (No.: 613/ H4.8.4.5.31/PP36-KOMETIK/2013).

\section{Measurement of Blood Pressure and Obesity Parameters}

Blood pressure was measured in rest conditions using digital tensimeter (Omron standard type HEM-7121, Omron 
Healthcare, Kyoto, Japan). Anthropometric measurements to obtain obesity parameters included BMI and WC. BMI was defined as body weight in $\mathrm{kg}$ divided by height in $\mathrm{m}^{2}$ $\left(\mathrm{kg} / \mathrm{m}^{2}\right)$. The obesity category was based on BMI adjusted to the Z-Score threshold in the Anthropometric Standard Assessment of Child Nutritional Status of the Ministry of Health of the Republic of Indonesia, with the criteria considered to be obese if $>2 \mathrm{SD}$ and normoweight -2 to 1 $\mathrm{SD} .^{21}$ Location of WC measurement was in the horizontal plane midway between lowest rib and the iliac crest. ${ }^{22} \mathrm{WC}$ was expressed in centimeters $(\mathrm{cm})$. The obesity category based on WC was determined based on the standard of Waist Circumference for Hong Kong Chinese Childhood, with the criteria considered to be obese if the WC was $\geq 86$ $\mathrm{cm}$ in men and dan $\geq 75 \mathrm{~cm}$ in women. ${ }^{23}$

\section{Calculation of Estimated GFR (eGFR)}

Calculation of eGFR based cys-C serum was using the eGFR-Chronic Kidney Disease Epidemiology Collaboration (eGFR-CKD EPI cys-C equation formula). The eGFR was expressed in $\mathrm{mL} / \mathrm{min} / 1.73 \mathrm{~m}^{2}$. A low eGFR value between $60-89 \mathrm{~mL} / \mathrm{min} / 1.73 \mathrm{~m}^{2}$ illustrated the decline in early stage kidney function. Classification of kidney function decline was based on National Kidney Foundation (NKF) Kidney Disease Outcomes Quality Initiative (K/ DOQI) criteria. ${ }^{14}$

\section{Examination of Cys-C, Adiponectin, Fasting Blood Glucose and Hemoglobin Alc (HbA1c)}

Blood samples were taken through the mediana cubital vein after the respondents fasted for 8 hours. All biomarker examinations were conducted at Prodia Clinical Laboratory, Makassar. Cys-C serum was examined by particle enhanced nephelometric immuno assay (PENIA) method (N Latex Cys-C, Siemens Healthcare, Munich, Germany). Reference serum cys-C level used was $0.50-0.96 \mathrm{mg} / \mathrm{dL}$. Serum adiponectin was examined by the enzyme-linked immunosorbent assay (ELISA) method (Sekisui Medical Company, Tokyo, Japan) and the range of serum adiponectin levels was 2.58-6.06 $\mu \mathrm{g} / \mathrm{mL}$ for men and 3.58-9.66 $\mu \mathrm{g} / \mathrm{mL}$ for women. $\mathrm{HbA} 1 \mathrm{c}$ was measured by the ion exchange high performance liquid chromatography HPLC method (Biorad, California, USA) with a normal HbA1c value of $<5.7 \%$. Fasting blood glucose was examined by the glucose oxidase - peroxidase aminoantypirin (GOD-PAP) method (Gluc2, Roche, Basel, Switzerland) with a normal reference value between $70-110 \mathrm{mg} / \mathrm{dL}$.

\section{Statistical Analysis}

The data obtained was processed using SPSS 24 (IBM Coorporation, New York, USA) for windows and then analyzed with a significance level of $\leq 0.05$. All data were presented in the form of a mean, standard deviation, median and percentile. Before testing the difference hypothesis and correlation, data were tested for normality and homogeneity. In addition to knowing the relationship, a correlation test was also conducted to assess the direction and strength of the correlation. Independent sample $t$ test was used to determine differences in serum cys- $\mathrm{C}$ and adiponectin levels between obese and normoweight adolescents. The spearman correlation test was used to determine the correlation between WC, sistolic blood pressure (SBP) and diastolic blood pressure (DBP) with serum cys-C and adiponectin levels. The pearson correlation test was used to determine the correlation between BMI and serum cys-C and adiponectin levels. Linear regression analysis was carried out to determine the most influential variables in determining serum cys-C and adiponectin levels.

\section{Results}

\section{Characteristics of Respondents}

Out of the 50 respondents, 30 of them were men. Table 1 showed the data on physical and anthropometric examinations. Significant differences were found for all parameter between obese and normoweight adolescents $(p<0.05)$. In addition to BMI, WC as a central obesity parameter was higher in obese adolescents compared to normoweight adolescents. Likewise with the results of blood pressure measurements both systole and diastole. Although there were differences, the value of blood pressure was still within normal limits.

\section{Differences in Serum Cys-C and Adiponectin Levels in Obese and Normoweight Adolescents}

Table 2 showed differences in serum cys-C and adiponectin levels between obese and normoweight adolescents. Cys-C levels in obese adolescents were higher than normoweight adolescents $\quad(0.80 \pm 0.10 \quad \mathrm{mg} / \mathrm{dL} \quad v s . \quad 0.71 \pm 0.10 \quad \mathrm{mg} / \mathrm{dL}$, $p<0.01)$. Although the average cys-C level was higher in obese adolescents than normoweight adolescents, but the mean levels in both groups were still in the normal range. In contrast, the serum adiponectin levels in obese adolescents were lower than those of normoweight adolescents $(3.62 \pm 1.38 \mu \mathrm{g} / \mathrm{L} v s .4 .75 \pm 1.94 \mu \mathrm{g} / \mathrm{L}, p<0.01)$. 
Table 1. Participants' characteristics.

\begin{tabular}{lccc}
\hline \multicolumn{1}{c}{ Variable } & $\begin{array}{c}\text { Obese } \\
(\mathbf{n = 2 8})\end{array}$ & $\begin{array}{c}\text { Normoweight } \\
(\mathbf{n = 2 2})\end{array}$ & $\boldsymbol{p}$-value \\
\hline Sex (boy/girl) & $23 / 5$ & $7 / 5$ & - \\
Age (years) & $15 \pm 0.51$ & $15 \pm 0.30$ & 0.01 \\
BMI (kg/m²) & $29.66 \pm 2.11$ & $20.68 \pm 2.61$ & $<0.001$ \\
WC (cm) & $102.25 \pm 12.42$ & $73.09 \pm 6.01$ & $<0.001$ \\
SBP (mmHg) & $120.54 \pm 11.25$ & $104.55 \pm 12.04$ & $<0.001$ \\
DBP (mmHg) & $75.54 \pm 7.11$ & $68.18 \pm 8.38$ & $<0.01$ \\
Body weight (kg) & $85.04 \pm 11.81$ & $56.73 \pm 8.51$ & $<0.001$ \\
Height (cm) & $169.04 \pm 9.62$ & $164.32 \pm 6.18$ & 0.05 \\
\hline
\end{tabular}

Value are expressed in mean $\pm \mathrm{SD} . \quad p$-value $<0.05$ for comparison between obese and normoweight groups.

The differences of these two biomarkers were also shown in Figure 1.

\section{Difference in eGFR-CKD EPI Cys-C Equation in Obese and Normoweight Adolescents}

Interestingly, the results of the calculation of eGFR based on cys-C serum (eGFR-CKD EPI cys-C equation) did not show differences although eGFR in obese adolescents were lower than adolescent normoweight $(119.75 \pm 13.2 \mathrm{~mL} /$ $\mathrm{min} / 1.73 \mathrm{~m}^{2}$ vs. $\left.125.4 \pm 0.81 \mathrm{~mL} / \mathrm{min} / 1.73 \mathrm{~m}^{2}, p=0.06\right)$. This difference was also shown in Table 2 .

\section{Correlation between Serum Cys-C and Adiponectin Levels with Blood Pressure and Obesity Parameters}

Correlation between serum cys-C and adiponectin levels with SBP, DBP, BMI, and WC were shown in Table 3.
Positive correlations between serum cys-C and SBP were found $(r=0.513, p<0.05)$, DBP $(r=0.339, p<0.05)$, BMI $(r=0.342, p<0.05)$ and WC $(r=0.414, p<0.01)$. Serum adiponectin was negatively correlated with SBP $(r=-0.434$, $p<0.01)$, DBP $(r=-0.386, p<0.01)$, BMI $(r=-0.421, p<0.01)$ and WC $(r=-0.351, p<0.05)$.

\section{Multiple Regresi Linear Analysis on Risk Factor for Serum Cys-C and Adiponectin Levels}

The results of multiple linear regression analysis showed the risk factors that play a role in determining the increase in serum cys- $\mathrm{C}$ levels or a decrease in serum adiponectin levels (Table 4). The risk factors analyzed were BMI, WC, SBP and DBP. SBP was a risk factor for determining serum cys-C levels, the higher the SBP the higher the serum cys-C level $(\beta=0.447, p=0.040)$. In contrast to cys-C, BMI is a risk factor for determining a decrease in serum adiponectin levels, the higher the BMI the lower the serum adiponectin level $(\beta=-0.527, p=0.041)$.

\section{Discussion}

In this research, there were significant differences in cys-C levels between the obese group and the normoweight group where cys-C levels were higher in the obese group than in the normoweight group. The results of this research support previous researches where serum cys-C levels were higher in the obese group than in the overweight and control groups in both men and women. ${ }^{24}$ The results found in this research are different from the research conducted in the population of children and adolescents aged 6-20 years. They found that serum cys-C did not differ significantly between the obese and non-obese groups. ${ }^{9}$ The difference in research results obtained may be due to the obesity criteria used. The obesity

Table 2. Clinical and biomarkers parameters.

\begin{tabular}{lccc}
\hline \multicolumn{1}{c}{ Variable } & $\begin{array}{c}\text { Obese } \\
(\mathbf{n = 2 8})\end{array}$ & $\begin{array}{c}\text { Normoweight } \\
(\mathbf{n = 2 2})\end{array}$ & $\boldsymbol{p}$-value \\
\hline Fasting blood glucosa $(\mathrm{mg} / \mathrm{dL})$ & $85.50 \pm 7.25$ & $89.95 \pm 17.53$ & 0.68 \\
HbAlc $(\%)$ & $5.21 \pm 0.38$ & $5.23 \pm 0.56$ & 0.31 \\
Adiponectin $(\mu \mathrm{g} / \mathrm{L})$ & $3.62 \pm 1.38$ & $4.75 \pm 1.94$ & $<0.01$ \\
Cys-C $(\mathrm{mg} / \mathrm{dL})$ & $0.80 \pm 0.10$ & $0.71 \pm 0.10$ & $<0.01$ \\
eGFR-CKD EPI cys-C equation $\left(\mathrm{mL} / \mathrm{min} / 1.73 \mathrm{~m}^{2}\right)$ & $119.75 \pm 13.12$ & $125.41 \pm 10.81$ & 0.06 \\
\hline
\end{tabular}

Value are expressed in mean $\pm \mathrm{SD}$. $p$-value $<0.05$ for comparison parameters between obese and normoweight groups. 

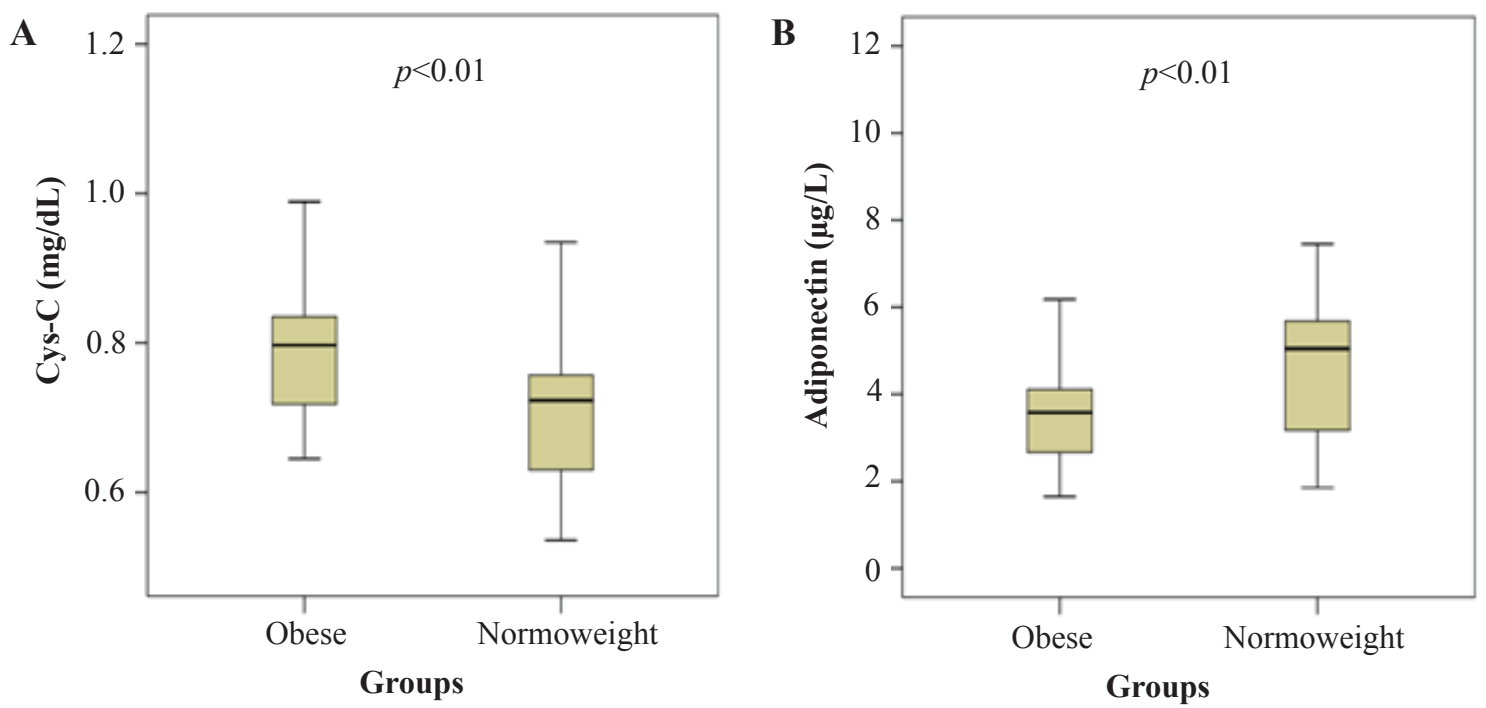

Figure 1. The comparison of serum cys-C and adiponectin levels between obese and normoweight adolescent. A: obese adolescent had significantly higher serum cys-C levels than normoweight adolescent; B: obese adolescent had significantly lower serum adiponectin levels than normoweight adolescent.

criteria in their research were only based on BMI while in this research based on BMI and WC. However, they also concluded that obesity causes renal hemodynamic changes such as hyperfiltration. Hyperfiltration occurs in the early stages of obesity. ${ }^{6}$

Cys-C levels in the obese group were higher than the normoweight group. This indicates that in obese adolescents there may have been a change in kidney hemodynamics which leads to early stage kidney damage. The obese group is more at risk for kidney problems than the normoweight group. Increased risk of ESRD on obesity is five times

Table 3. Correlation between serum cys-C and adiponectin level and other parameters in obese and normoweight group.

\begin{tabular}{lccccc}
\hline \multirow{2}{*}{ Variable } & \multicolumn{2}{c}{ Cys-C } & & \multicolumn{2}{c}{ Adiponectin } \\
\cline { 2 - 3 } \cline { 5 - 6 } & $\boldsymbol{r}$-value & $\boldsymbol{p}$-value & & $\boldsymbol{r}$-value & $\boldsymbol{p}$-value \\
\hline BMI $\left(\mathrm{kg} / \mathrm{m}^{2}\right)$ & 0.342 & $<0.05$ & & -0.421 & $<0.01$ \\
WC $(\mathrm{cm})$ & 0.414 & $<0.01$ & -0.351 & $<0.05$ \\
SBP $(\mathrm{mmHg})$ & 0.513 & $<0.05$ & -0.434 & $<0.01$ \\
DBP $(\mathrm{mmHg})$ & 0.339 & $<0.05$ & -0.386 & $<0.01$ \\
\hline
\end{tabular}

Data expressed as correlation coefficient ( $r$-value) and $p$-value. $p$-value $<0.05$. Serum cys-C and adiponectin level. were dependent variables. higher than individuals with normoweight. Visceral fat, insulin resistance and inflammation are strongly correlated with the occurrence of CKD and ESRD in obesity. ${ }^{6}$

Although the average cys-C level was higher in obese adolescents compared to normoweight adolescents, the majority of adolescent cys-C levels in this research were still in the normal range. This considered to be influenced by metabolic processes in adolescence is still on normal condition, including the formation and work of enzymes are still going on optimally. Good metabolism can provokes an appropriate cell regeneration, including regeneration of glomerular mesangial cells and renal tubular epithelial cells. ${ }^{25}$

Statistically, there were no differences of eGFR based-serum cys-C between obese and normoweight adolescents. This finding shows that obese adolescents have no difference in eGFR compared to normoweight adolescents if eGFR measurements use the eGFR-CKD EPI cys-C equation formula. This result is different from previous researches to determine glomerular filtration rates in children and adolescents who found that eGFR differed significantly between obese and non-obese groups. ${ }^{9}$ eGFR based on the cys-C equation has the highest correlation compared to eGFR based-creatinine in overweight and obese subjects. eGFR based cys-C is more accurate, sensitive and specific compared to eGFR based-creatinine in estimating eGFR in overweight and obese subjects. ${ }^{4} \mathrm{Cys}-\mathrm{C}$ 
Table 4. Linear regression analysis on risk factor for serum cys-C and adiponectin levels.

\begin{tabular}{lccccccc}
\hline \multirow{2}{*}{ Variable } & \multicolumn{3}{c}{ Cys-C } & \multicolumn{3}{c}{ Adiponectin } \\
\cline { 2 - 3 } \cline { 6 - 7 } & $\begin{array}{c}\text { Standard } \\
\text { Error }\end{array}$ & $\boldsymbol{\beta}$-Coefficients & $\boldsymbol{p}$-value & $\begin{array}{c}\text { Standard } \\
\text { Error }\end{array}$ & $\boldsymbol{\beta}$-Coefficients & $\boldsymbol{p}$-value \\
\hline SBP (mmHg) & 0.002 & 0.447 & 0.04 & 0.026 & -0.206 & 0.342 \\
DBP (mmHg) & 0.003 & -0.058 & 0.761 & 0.039 & -0.072 & 0.714 \\
BMI (kg/m $\left.{ }^{2}\right)$ & 0.006 & 0.173 & 0.488 & 0.084 & -0.527 & 0.041 \\
WC (cm) & 0.002 & -0.037 & 0.898 & 0.028 & -0.285 & 0.334 \\
\hline
\end{tabular}

$p$-value $<0.05$ for risk factor for serum cys-C and adiponectin.

levels in the blood represent eGFR and can be said to be close to the ideal endogenous eGFR marker. Compared with serum creatinine, cys- $\mathrm{C}$ is a biomarker that is useful for routine assessment of kidney function in adolescents. Although it is not statistically different, the average eGFR in obese adolescents was lower than that of normoweight adolescents. Perhaps renal hemodynamic changes such as hyperfiltration have occurred in the obese group although the average eGFR in the obese group is still normal.

The results of the analysis to determine the correlation between BMI and WC with cys-C levels obtained a linear correlation. Although the strength of the correlation obtained is weak (between cys-C and BMI) and moderate (between cys-C and $\mathrm{WC}$ ), the direction of positive correlation means that when BMI and WC become higher, the level of cys-C would follow. Serum cys-C is influenced by many factors including the increase height and weight. ${ }^{24} \mathrm{Cys}-\mathrm{C}$ correlates strongly with central obesity parameters (WC and waist hip ratio) compared to BMI and is a predictor of cardiovascular disease and much better used as a predictor of metabolic syndrome compared with BMI. ${ }^{26}$ In obesity based on BMI, it is known that adipocytes are able to produce and secrete a number of proteins including cys-C which affect various physiological processes. The expression level messenger RNA (mRNA) of cys-C in subcutaneous tissue and adipose omentum is twice higher than non-adipose tissue. ${ }^{27}$ In children and adolescents, it is also found a positive correlation between BMI and cys-C levels. ${ }^{10}$

Kidney function may be a very important determinant in controlling SBP. ${ }^{28}$ This is based on the results of the linear regression multivariate test that $\mathrm{SBP}$ is a predictor factor for the increase in serum cys-C levels compared to DBP, BMI and WC. Previous researches found the same where cys-C was significantly and linearly related to SBP but not with DBP in subjects categorized by kidney function based on cys-C serum..$^{26,27}$ This correlation may have important implications in the treatment of hypertension. ${ }^{29}$ Another research also found that cys- $\mathrm{C}$ can be used as a biomarker to detect and prevent a decrease in mild kidney function to prevent the risk of cardiovascular events in hypertensive patients with normal kidney function. ${ }^{30}$

Analysis to find out the correlation between blood pressure and cys-C obtained a linear correlation. SBP correlates with cys-C. The correlation coefficient value indicates that the direction of the positive correlation with the moderate correlation strength. DBP also correlates with cys-C. Correlation coefficient value means that the positive correlation direction with hesitant correlation strength. The direction of positive correlation means the higher the blood pressure, the higher the level of cys-C. It is similar to previous research which found that cys-C levels correlated with blood pressure, both SBP and DBP. ${ }^{31}$

In this research, there were significant differences in adiponectin levels between the obese and normoweight groups where adiponectin levels in the obese group were lower than the normoweight group. This indicates that in obese adolescents there has been a mediator balance disorder of anti-inflammatory and pro-inflammatory in the early stage due to adiposopathy. ${ }^{32}$ An anti-inflammatory mediator whose levels are decreased is adiponectin. Low levels of adiponectin is also caused by loss of adiponectin receptor population in the liver and muscles. ${ }^{33}$ In addition, the autophagy process plays an important role in reducing adiponectin levels due to stress on the endoplasmic reticulum of adipocyte cells. This is the basis of the downregulation process for adiponectin in obesity. ${ }^{34}$ The results of this research also support previous researches, which found thet adiponectin levels were lower in the obese group than the normoweight group in pre-puberty subjects. ${ }^{19}$ 
Analysis to determine the correlation between adiponectin and blood pressure and obesity parameters obtained a linear correlation. Adiponectin correlates with BMI. The correlation coefficient value indicates that the direction of the negative correlation with moderate correlation strength. The higher the BMI, the lower the level of adiponectin. Previous research gave similar results in adult female subjects ${ }^{35}$ and obese non-diabetic women ${ }^{36}$.

The WC correlates with adiponectin levels even though the correlation strength obtained is weak. The higher the WC, the lower the level of adiponectin. The direction of negative correlation means that adiponectin levels in adolescents with a large WC have lower adiponectin levels than adolescents with normal WC. The same was reported from previous researches which proved a negative correlation of adiponectin with WC in men. It is known that central obesity which is characterized by a buildup of fat in visceral organs is associated with metabolic disorders. ${ }^{35}$

Blood pressure also correlates with adiponectin levels. Between SBP and adiponectin showed that the higher the SBP, the lower the level of adiponectin. Between DBP and adiponectin also showed that higher DBP the lower adiponectin levels. We obtained the results that support several previous researches. Although it is still speculative, adiponectin correlates with blood pressure in obese children. ${ }^{37}$ Plasma adiponectin levels can be used as a biomarker for hypertension ${ }^{38}$ and a decrease in adiponectin levels in possible hypertension mediated by adiposity. Decreased adiponectin in obese patients is also associated with endothelial dysfunction ${ }^{39}$. It is also possible that obese individuals with metabolic syndrome have an adiponectin gene polymorphism which triggers an increase in blood pressure. ${ }^{40}$

Multivariate linear regression test was carried out on four parameters in this research to predict a decrease in adiponectin levels. Only BMI shows correlation. This indicates that BMI can be used as a predictor factor for the occurrence of inflammation in obese adolescents characterized by a decrease in proinflammatory mediators, one of which is adiponectin.

\section{Conclusion}

There is an increase in serum cys- $\mathrm{C}$ levels and a decrease in serum adiponectin in obese adolescents compared to normal weight adolescents and plays a role in the pathomechanism of decreased renal function and inflammation in obese adolescents. Cys-C has a positive correlation with blood pressure, BMI and WC. This is the contrary to the adiponectin. SBP is a predictor factor in increasing cys-C levels and BMI is a predictor factor of inflammation in obese adolescents. Subsequent research emphasized the differences in cys- $\mathrm{C}$ and adiponectin levels in central obese adolescents.

\section{References}

1. Ding W, Cheung WW, Mak RH. Impact of obesity on kidney function and blood pressure in children. World J Nephrol. 2015; 4(2): 223-9.

2. Mead E, Atkinson G, Richter B, Metzendorf MI, Baur L, Finer N, et al. Drug interventions for the treatment of obesity in children and adolescents. Cochrane Database Syst Rev. 2016; 0(11): 1-44. doi: 10.1002/14651858.CD012436.

3. Eknoyan G. Obesity and chronic kidney disease. Nefrologia. 2011; 31(4): 397-403.

4. Marwyne MNN, Loo CY, Halim AG, Norella K, Sulaiman T, Zaleha MI. Estimation of glomerular filtration rate using serum cystatin $\mathrm{C}$ in overweight and obese subjects. Med J Malaysia. 2011; 66(4): 313-7.

5. Niu H, Li Y, Li H, Chi Y, Zhuang M, Zhang T, et al. Matrix metalloproteinase 12 modulates high-fat-diet induced glomerular fibrogenesis and inflammation in a mouse model of obesity. Sci Rep. 2016; 6(20171): 1-14.

6. Zoccali C. Overweight, obesity and metabolic alterations in chronic kidney disease. Sec Biol Med Sci. 2009; 31(2): 17-31.

7. Rouhani M, Kelishadi R, Hashemipour M, Esmailzadeh A, Surkan PJ, Keshavarz A, et al. The impact of a low glycemic index diet on inflammatory markers and serum adiponectin concentration in adolescent overweight and obese girls : a randomized clinical trial. Horm Metab Res. 2016; 48(4): 251-6.

8. Rocha VZ, Folco EJ. Inflammatory concepts of obesity. Int J Inflam. 2011; 2011: 529061. doi: 10.4061/2011/529061.

9. Jung Y, Kim D, Lim I. The Relation between GFR and obesity in children and adolescent obese. Korean Journals Pediatr. 2005; 48(11): 1219-24.

10. Marmarinos A, Garoufi A, Panagoulia A, Dimou S, Drakatos A, Paraskakis I, et al. Cystatin-C levels in healthy children and adolescents: Influence of age, gender, body mass index and blood pressure. Clin Biochem. 2016; 49(1): 150-3.

11. Ouchi N, Walsh K. Adiponectin anti inflammation. Clin Chim Acta. 2009; 380(1-2): 24-30.

12. Lafarge JC, Naour N, Clément K, Guerre-Millo M. Cathepsins and cystatin $\mathrm{C}$ in atherosclerosis and obesity. Biochimie. 2010; 92(11): 1580-6.

13. Papadopoulou-Marketou N, Skevaki C, Kosteria I, Peppa M, Chrousos GP, Papassotiriou I, et al. NGAL and cystatin C : two possible early markers of diabetic nephropathy in young patients with type 1 diabetes mellitus : one year follow up. Hormones. 2015; 14(2): 232-40.

14. National Kidney Foundation. K/DOQI clinical practice guidelines for chronic kidney disease: evaluation, clasification and stratification. Am J Kidney Dis. 2002; 39 (2 Suppl 1): S1-266.

15. Ito R, Yamakage $\mathrm{H}$, Kotani K, Wada H, Otani S, Yonezawa K, et al. Comparison of cystatin $\mathrm{C}$ and creatinine-based estimated 
glomerular filtration rate to predict coronary heart disease risk in Japanese patients with obesity and diabetes. Endocr J. 2015; 62(2): 201-7.

16. Asayama K, Hayashibe H, Dobashi K, Uchida N, Nakane T. Decrease in serum adiponectin level due to obesity and visceral fat accumulation in children. Obes Res. 2003; 11(9): 1072-9.

17. Diwan AG, Kuvalekar AA, Dharamsi S, Vora AM, Nikam VA, Ghadge AA. Correlation of serum adiponectin and leptin levels in obesity and type 2 diabetes mellitus. Indian J Endocrinol Metab. 2018; 22(1): 93-9.

18. Jain V, Kumar A, Agarwala A, Vikram N, Ramakrishnan L. Adiponectin, interleukin- 6 and high-sensitivity c-reactive protein levels in overweight/obese indian children. Indian Pediatr. 2017; 54(10): 848-50.

19. Medina-Bravo P, Meza-Santibanez R, Rosas-Fernandez P, GalvanDuarte R, Saucedo-Garcia R, Velazquez-Lopez L, et al. Decrease in serum adiponectin levels associated with visceral fat accumulation independent of pubertal stage in children and adolescents. Arch Med Res. 2011; 42(2): 115-21.

20. Kazumi T, Kawaguchi A, Hirano T, Yoshino G. Serum adiponectin is associated with high-density lipoprotein cholesterol, triglycerides, and low-density lipoprotein particle size in young healthy men. Metabolism. 2004; 53(5): 589-93.

21. Kementerian Kesehatan Republik Indonesia. Standar Antropometri Penilaian Status Gizi Anak. Jakarta: Kementerian Kesehatan Republik Indonesia; 2010.

22. Ma WY, Yang CY, Shih SR, Hsteh HJ, Hung CS, Lin MS, et al. Measurement of waist circumference: midabdominal or iliac crest?. Diabetes Care. 2013; 36(6): 1660-6.

23. Sung RY, So HK, Choi KC, Nelson EAS, Li AM, Yin JAT, et al. Waist circumference and waist-to-height ratio of hong kong chinese children. BMC Public Health. 2008; 8(1): 324. doi: 10.1186/14712458-8-324.

24. Bashir R, Imtiaz S, Yasir M, Raza H, Mohsin S, Shah ALI. Effect of body mass index on serum cystatin $\mathrm{C}$ level in healthy subjects. PJMHS. 2010; 4(4): 17-20.

25. Chou YH, Pan SY, Yang CH, Lin SL. Stem cells and kidney regeneration. J Formos Med Assoc. 2014; 113(4): 201-9.

26. Panaich SS, Veeranna V, Bavishi C, Zalawadiya SK, Kottam A, Afonso L. Association of cystatin C with measures of obesity and its impact on cardiovascular events among healthy US adults. Metab Syndr Relat Disord. 2014; 12(9): 472-6.

27. Naour N, Fellahi S, Renucci JF, Poitou C, Rouault C, Basdevant A, et al. Potential contribution of adipose tissue to elevated serum cystatin C in human obesity. Obesity. 2009; 17(12): 2121-6.

28. Sur A, Pk M, Swain M, Mohapatra N. Study of relationship between kidney function and systolic blood pressure : new insights from cystatin C. Biochem Anal Biochem. 2015; 4(4): 1-5.

29. Peralta CA, Whooley MA, Ix JH, Shlipak MG. Kidney function and systolic blood pressure new insights from cystatin C: data from the heart and soul study. Am J Hypertens. 2009; 19(9): 939-46.

30. Salgado JV, Salgado BJ, Neves FA. Cystatin C may better reflect the effect of obesity on renal function. Obesity. 2012; 20(6): 1136. doi: 10.1038/oby.2011.366.

31. Jovanovic M, Kavaric N, Gligorovic-barhanovic N, Skerovic V. Cystatin $\mathrm{C}$ in healthy middle-aged adults: a relationship with anthropometric and cardiometabolic parameters. J Heal Sci. 2016; 6(2): 105-111.

32. Francisco V, Pino J, Campos-cabaleiro V, Ruiz-Fernandez C, Mera A, Gonzalez-Gay MA, et al. Obesity, fat mass and immune system : role for leptin. Front Physiol. 2018; 9(640): 1-20.

33. Ignacio RMC, Kim C, Kim S. Lifestyle immunological profiling of obesity. J Lifestyle Med. 2014; 4(1): 1-7.

34. Zhou H, Zhao J, Zhang X. Inhibition of uncoupling protein 2 by genipin reduces insulin-stimulated glucose uptake in 3T3-L1 adipocytes. Arch Biochem Biophys. 2009; 486(1): 88-93.

35. Okauchi Y, Kishida K, Funahashi T, Noguchi M, Ogawa T, Ryo $\mathrm{M}$, et al. Changes in serum adiponectin concentrations correlate with changes in BMI, waist circumference, and estimated visceral fat area in middle-aged general population. Diabetes Care. 2009; 32(10): 122. doi: $10.2337 / \mathrm{dc} 09-1130$.

36. Mamaghani F, Zarghami N, Maleki MJ, Pourhassan-Moghaddam M HF. Variation of adiponectin levels in normal and obese subjects: possible correlation with lipid profiles. Int J Endocrinol Metab. 2009; 3: 170-8.

37. Yin $\mathrm{C}, \mathrm{Chu} \mathrm{H}, \mathrm{Li} \mathrm{H}$, Xiao Y. Plasma Sfrp5 and adiponectin levels in relation to blood pressure among obese children. J Hum Hypertens. 2016; 31: 284-91.

38. Kim DH, Kim C, Ding EL, Townsend MK, Lipsitz LA. Adiponectin levels and the risk of hypertension : a systematic review and metaanalysis. Adiponectin. 2013; 62(1): 27-32.

39. Rojas E, Rodríguez-Molina D, Bolli P, Israili ZH, Faría J, Fidilio $\mathrm{E}$, et al. The role of adiponectin in endothelial dysfunction and hypertension. Curr Hypertens Rep. 2014; 16(8): 1-8.

40. Zhao T, Zhao J. Genetic effects of adiponectin on blood lipids and blood pressure. Clin Endocrinol. 2011; 74(2): 214-22. 